УДК 550.8 .053

\title{
ВЫДЕЛЕНИЕ ПЕТРОФИЗИЧЕСКИХ ТИПОВ КАРБОНАТНЫХ ПОРОД ПО ДАННЫМ ЯДЕРНОГО МАГНИТНОГО РЕЗОНАНСА С УЧЕТОМ ИХ ЛИТОЛОГИЧЕСКИХ ОСОБЕННОСТЕЙ
}

\author{
Путилов Иван Сергеевич ${ }^{1}$ \\ Ivan.Putilov@pnn.lukoil.com
}

\author{
Разницын Александр Вячеславович1, \\ alexandrraznitsyn@gmail.com \\ 1 Филиал ООО «ЛУкОЙЛ-Инжиниринг» «ПермНИПИнесть» в г. Перми, \\ Россия, 614015, г. Пермь, ул. Пермская, За.
}

\begin{abstract}
Актуальность. Значительная часть мировых запасов углеводородов приурочена к карбонатным резервуарам, характеризующимся сложным строением пустотного пространства. Подсчет запасов и проектирование разработки таких залежей требуют детального изучения структуры пустотного пространства, которая напрямую определяет коллекторские свойства пород. Выделение петрофизических классов пород является неотъемлемой частью построения петрофизической модели залежи углеводородов. Метод ядерного магнитного резонанса (ЯМР) является одним из методов изучения структуры пустотного пространства горных пород и имеет ряд преимуществ перед другими методами. Однако в опубликованной литературе отсутствует информация о применении данного метода для решения задач петротипизации. Результаты выделения петрофизических классов на основе комплексирования данных ядерного магнитного резонанса и микролитологического описания шлифов позволят значительно улучшить качество петрофизического обеспечения геологического и гидродинамического моделирования залежи и, следовательно, повысить точность подсчета запасов углеводородов и эффрективность их разработки.

Цель: выделение петрофизических типов карбонатных пород на основе комплексирования данных ядерного магнитного резонанса и микроописания шлифов, а также оценка правильности выделения классов методами математической статистики. объект: карбонатные породы формации Мишриф, являющейся продуктивной в разрезе одного из месторождений Месопотамской нефтегазоносной провинции.

Методы: анализ результатов ЯМР-исследований образцов керна, микроописания шлифов и стандартных лабораторных исследований керна, методы математической статистики.

Результаты. На основе комплексного анализа результатов ЯМР-исследований керна и микроописания шлифов выделены три петрофизических класса в разрезе изучаемой скважины, вскрывшей продуктивные отложения: образцы со структурами породы вакстоун и вакстоун/фрлаутстоун объединены в 1 класс, со структурами пакстоун, грейнстоун и рудстоун - во 2 класс, и со структурой фреймстоун - в 3 класс. Данная петротипизация подтверждена результатами статистического анализа.
\end{abstract}

\section{Ключевые слова:}

Петрофризический тип, метод ядерного магнитного резонанса, классификация Р. Данема, время поперечной релаксации, карбонатные породы, статистический анализ.

\section{Введение}

Явление ядерного магнитного резонанса (ЯМР), начиная с 90-х гг. XX в., широко используется при изучении петрофизических свойств коллекторов нефти и газа (как в лаборатории, так и в скважине ядерный магнитный каротаж), а также исследовании свойств пластовых флюидов [1]. Исследования горных пород и флюидов методом ЯМР основаны на изучении резонансного поглощения электромагнитной энергии ядрами атомов водорода. Физические основы явления ЯМР подробно описаны в работе И.С. Джафарова, П.Е. Сынгаевского и С.Ф. Хафизова «Применение метода ядерного магнитного резонанса для характеристики состава и распределения пластовых флюидов» [2]. Метод ЯМР является уникальным неразрушающим методом исследования горных пород и позволяет определять такие важные характеристики коллекторов, как коэффициенты пористости и остаточной водонасыщенности, структуру порового пространства, распределение по типам пористости, смачиваемость и многие другие [3-12].
При выполнении лабораторных ЯМРисследований, как правило, проводят измерение времен поперечной релаксации (ввиду того, что поперечная релаксация протонов происходит быстрее, чем продольная, что значительно сокращает время проведения эксперимента). Известно, что при полном насыщении образца керна одним флюидом с известным водородным индексом и отсутствии градиента магнитного поля доминирующим механизмом релаксации ядер является их релаксация на поверхности пор. Время поперечной релаксации в этом случае определяется следующим выражением [2]:

$$
\frac{1}{\mathrm{~T}_{2}}=\rho \frac{S}{V},
$$

где $\mathrm{T}_{2}$ - время поперечной релаксации, мс; $\rho$ - peлаксационная активность породы, мкм/мс; S/V площадь удельной поверхности порового пространства, мкм ${ }^{2} /$ мкм $^{3}$.

Как видно из выражения (1), отношение площади поры (S) к ее объему (V) пропорционально обратной величине размера поры, а время поперечной релаксации $\mathrm{T}_{2}$, в свою очередь, пропорцио- 
нально размеру поры. Таким образом, метод ЯМР при определенных условиях (насыщение образца одним флюидом и отсутствие градиента магнитного поля) можно рассматривать в качестве метода изучения структуры пустотного пространства горных пород, применение которого в отличие от других известных методов позволяет сократить временные и трудовые затраты, а также получить ряд других важных петрофизических характеристик (комплексный метод).

Выделение петрофизических типов пород является одним из этапов построения петрофизической модели, лежащей в основе геологической модели залежи углеводородов [13]. Как правило, разделение пород на классы основано на взаимосвязи размеров пор и структурных особенностей [14], размерах поровых каналов [15], единиц гидравлического потока (FZI) [16] и др. [17].

В данной работе выделение петрофизических классов карбонатных пород проведено на основе комплексного анализа результатов микроописания шлифов и ЯМР-исследований керна, а именно на взаимосвязи структуры отложений и структуры пустотного пространства пород.

Объектом исследования является формация Мишриф, представляющая собой один из продуктивных комплексов изучаемого нефтяного месторождения Месопотамской нефтегазоносной провинции [18]. Исследуемые отложения изучены по керну и представлены чередованием известняков от светло-серой до бурой окраски, в различной степени доломитизированных, неравномерно пористых, прослоями органогенно-детритовых, неравномерно битуминизированных. Накопление осадков происходило в сеноман-раннетуронское время позднемеловой эпохи в условиях шельфовой окраины палеоокеана Тетис.

\section{Структурная характеристика изучаемых отложений}

Структура изучаемых отложений охарактеризована по классификации карбонатных пород Р. Данема, дополненной А. Эмбри и Дж. Кловеном в интерпретации В.Г. Кузнецова. При разделении карбонатных пород здесь учитываются такие факторы, как наличие или отсутствие первичных структур, количественные соотношения между первичными форменными элементами и цементом, форма, размер и степень упаковки компонентов, структура цемента (основной массы), характер кристаллов. Являясь прежде всего структурной, данная классификация также несет определенный генетический смысл, отражая прежде всего динамику среды отложения. Так, по мере увеличения гидродинамической активности возрастает количество скелетного материала, сокращается количество микрита при одновременном увеличении спарита [19].

В данной работе анализируются результаты ЯМР-исследований 91 образца керна со следующими структурами пород по Р. Данему [19]:

1) Вакстоун (49 образиов) - микро- и тонкозернистый известняк с достаточно обильным содержа- нием (до 40-50\%) форменных элементов размером менее 2 мм. Обязательным условием определения структуры является погружение форменных компонентов в ил без их соприкосновения.

2) Вакстоун/флаутстоун (14 образиов) - промежуточная структура. Флаутстоун - известняк, состоящий из форменных элементов размером более 2 мм, с микро-тонкозернистым цементом порового и базального типов. Флаутстоуны характеризуют спокойную гидродинамическую среду седиментации.

3) Пакстоун (8 образиов) - известняк, состоящий из форменных элементов размером менее 2 мм, с тонко-микрозернистым цементом порового и базального типов. Для этой структуры характерно соприкосновение зерен друг с другом. Пакстоуны накапливались в обстановках с неустойчивой гидродинамикой среды;

4) Грейнстоун (13 образцов) - известняк, состоящий из форменных элементов размером менее 2 мм, с яснокристаллическим (спаритовым) цементом порового и базального типов. Опорой («каркасом») структуры являются зерна. Эта структура по уровню энергоемкости самая высшая. Отсутствие ила и наличие спарита свидетельствуют о «промытости» породы.

5) Рудстоун (3 образиа) - известняк, состоящий из форменных элементов размером более 2 мм, с яснокристаллическим (спаритовым) цементом порового типа. Зерна опираются друг на друга, образуя «каркас» породы. Формирование этой структуры происходило в условиях высокой активности водной среды, причем чем меньше размерность структурных компонентов породы, тем выше динамическая характеристика среды осадконакопления.

6) Фреймстоун (4 образиа) - автохтонный известняк, в котором массивные формы ископаемых организмов образуют во время осадконакопления прочный трехмерный остов, промежутки которого могли заполняться карбонатным материалом другой структуры или оставаться пустыми.

\section{Выделение петрофизических типов изучаемых отложений}

Одним из факторов, оказывающих существенное влияние на структуру пустотного пространства пород, а следовательно, и на фильтрационно-емкостные свойства (ФЕС) является структура породы $[20,21]$. Поэтому первичное разделение образцов керна изучаемых отложений основано на результатах литологического микроописания шлифов.

Для изучения петрофизических характеристик выделенных групп образцов в работе используются следующие показатели, полученные в результате интерпретации данных ЯМР-исследований:

1. Коэффициент общей пористости $\left(\mathrm{K}_{\Pi}\right)$.

2. Распределение времен поперечной релаксации $\mathrm{T}_{2}$ по типам пористости (вклад в общую пористость), включающее: 
- глинисто-связанную воду (CBW) и микропористость (отделяется по общепринятой [22] граничной отсечке $\left.\mathrm{T}_{2}=3 \mathrm{Mc}\right)$;

- капиллярно-связанную воду (отделяется по двум граничным отсечкам - 3 мс и $\mathrm{T}_{2 \text { гр }}$, определенной методом граничной отсечки [2]);

- эффективную пористость (отделяется по двум граничным отсечкам - $\mathrm{T}_{2 \text { гр }}$, определенной методом граничной отсечки, и общепринятой граничной отсечке $\mathrm{T}_{2}=750 \mathrm{Mc}$ [22]);

- каверновую пористость (отделяется по граничной отсечке $750 \mathrm{Mc})$.

3. Коэффициент остаточной водонасыщенности $\mathrm{K}_{\mathrm{oв}}$, определенный по методу граничной отсечки и соответствующее время граничной отсечки $\mathrm{T}_{2 г \mathrm{p}}$.

4. Индекс свободного флюида FFI, определяемый как сумма эффективной и каверновой пористостей.

5. Отношение индекса свободного флюида к индексу связанной воды FFI/BVI.

6. Модальное значение времени поперечной релаксации $\mathrm{T}_{2}$ mode.

7. Логарифмическое среднее $T_{2} \operatorname{logmean}$, определяемое по формуле:

$$
T_{2} \text { logmean }=10^{\frac{\Sigma K_{n} \log \left(T_{2 j}\right)}{\Sigma \mathrm{K}_{\Pi i}},}
$$

где $\mathrm{K}_{\text {пі }}$ - $\mathrm{i}$-я пористость, соответствующая j-му значению $\mathrm{T}_{2 \mathrm{j}}$.
В табл. 1 приведены основные статистические характеристики результатов ЯМР-исследований раздельно для образцов с различной структурой породы по Р. Данему. По приведенным средним данным видно, что наилучшими коллекторскими свойствами обладают образцы со структурой фреймстоун $\left(\mathrm{K}_{\text {п }}(\right.$ ЯМР $)=17,76 \%, \mathrm{~K}_{\text {ов }}$ (ЯМР $)=11,50 \%$, $\mathrm{FFI}=88,50 \%$, FFI/BVI=8,06), наихудшими - образцы со структурой вакстоун $\left(\mathrm{K}_{\text {п }}(\right.$ ЯМР $)=10,85 \%, \mathrm{~K}_{\text {ов }}$ $($ ЯMP $)=71,73 \%, \mathrm{FFI}=28,27 \%$, FFI $/ \mathrm{BVI}=0,49)$.

С целью определения статистических различий образцов с разной структурой пород по средним значениям результатов ЯМР-исследований был применен t-критерий Стьюдента (табл. 2) [23]. Среди анализируемых показателей наиболее информативными (по средним значениям которых изучаемые группы образцов статистически отличаются друг от друга) являются коэффициент остаточной водонасыщенности $\left(\mathrm{K}_{\text {ов }}\right)$, содержание капиллярно-связанной воды (BVI), каверновая пористость, индекс свободного флюида (FFI), отношение индекса свободного флюида к индексу связанного флюида (FFI/BVI), модальное значение времени поперечной релаксации ( $\mathrm{T}_{2}$ mode), логарифмическое среднее значение времени поперечной релаксации $\left(\mathrm{T}_{2} \operatorname{logmean}\right)$. При этом стоит отметить, что ни по каким показателям не разделяются между собой образцы со структурами пакстоун, грейнстоун и рудстоун, что свидетельствует о близких значениях результатов ЯМР-исследований и, следовательно, о схожей структуре пустотного пространства.

Таблица 1. Основные статистические характеристики результатов ЯМР-исследований образиов с различной структурой породы

Table 1. The main statistical characteristics of the different rock structure samples nuclear magnetic resonance (NMR) experiments results

\begin{tabular}{|c|c|c|c|c|c|c|}
\hline \multirow[b]{2}{*}{$\begin{array}{l}\text { Параметры } \\
\text { Parameters }\end{array}$} & \multicolumn{6}{|c|}{$\begin{array}{c}\text { Тип структуры по Р. Данему } \\
\text { Rock structure type (R. Dunham classification) }\end{array}$} \\
\hline & $\begin{array}{l}\text { Вакстоун } \\
\text { Wackestone }\end{array}$ & $\begin{array}{c}\text { Вакстоун/ } \\
\text { флаутстоун } \\
\text { Wackestone/ } \\
\text { Floatstone }\end{array}$ & $\begin{array}{l}\text { Пакстоун } \\
\text { Packstone }\end{array}$ & $\begin{array}{l}\text { Грейнстоун } \\
\text { Grainstone }\end{array}$ & $\begin{array}{l}\text { Рудстоун } \\
\text { Rudstone }\end{array}$ & $\begin{array}{l}\text { Фреймстоун } \\
\text { Framestone }\end{array}$ \\
\hline $\mathrm{K}_{\text {п }}($ ЯМР), \% & $\frac{10,85 \pm 5,09}{3,42-23,08}$ & $\frac{16,52 \pm 6,44}{6,18-24,35}$ & $\frac{21,22 \pm 2,92}{15,75-24,13}$ & $\frac{17,47 \pm 9,38}{5,20-32,07}$ & $\frac{15,67 \pm 7,77}{9,37-24,35}$ & $\frac{17,76 \pm 2,56}{14,52-20,79}$ \\
\hline $\mathrm{T}_{2 \mathrm{rp}}, \mathrm{Mc}(\mathrm{ms})$ & $\frac{111,88 \pm 48,78}{55,00-344,00}$ & $\frac{113,07 \pm 33,23}{69,00-175,00}$ & $\frac{131,88 \pm 41,44}{83,00-220,00}$ & $\frac{159,15 \pm 62,76}{45,00-282,00}$ & $\frac{98,67 \pm 46,23}{70,00-152,00}$ & $\frac{83,50 \pm 32,54}{60,00-129,00}$ \\
\hline $\begin{array}{l}\mathrm{K}_{\text {ов }} \text { (ЯMP), \% } \\
\mathrm{K}_{\mathrm{wir}}(\mathrm{NMR}), \% \\
\end{array}$ & $\frac{71,73 \pm 13,84}{29,43-94,02}$ & $\frac{60,05 \pm 22,10}{25,09-89,16}$ & $\frac{31,08 \pm 15,27}{15,45-54,38}$ & $\frac{32,63 \pm 16,08}{11,06-61,30}$ & $\frac{23,84 \pm 9,54}{13,29-31,85}$ & $\frac{11,50 \pm 2,67}{10,03-15,50}$ \\
\hline $\begin{array}{l}\text { Глинисто-связанная вода + } \\
\text { микропористость } * \text {, \% } \\
\text { Clay-bound } \\
\text { water + microporosity, \% }\end{array}$ & $\frac{3,24 \pm 2,91}{0,00-13,36}$ & $\frac{1,24 \pm 1,07}{0,00-3,20}$ & $\frac{0,27 \pm 0,19}{0,00-0,64}$ & $\frac{0,63 \pm 1,11}{0,00-3,46}$ & $\frac{0,56 \pm 0,50}{0,08-1,07}$ & $\frac{0,12 \pm 0,14}{0,00-0,24}$ \\
\hline $\begin{array}{l}\text { Капиллярно-связанная вода*, \% } \\
\text { Capillary-bound water, \% }\end{array}$ & $\frac{68,49 \pm 13,08}{28,65-90,18}$ & $\frac{58,80 \pm 21,69}{25,09-87,19}$ & $\frac{30,81 \pm 15,22}{15,09-54,18}$ & $\frac{32,00 \pm 15,46}{10,70-58,65}$ & $\frac{23,28 \pm 9,06}{13,21-30,78}$ & $\frac{11,39 \pm 2,60}{9,89-15,28}$ \\
\hline $\begin{array}{l}\text { Эффективная пористость*, \% } \\
\text { Free fluid porosity, \% }\end{array}$ & $\frac{25,86 \pm 12,37}{2,98-65,20}$ & $\frac{35,24 \pm 18,77}{9,83-66,66}$ & $\frac{49,08 \pm 12,24}{30,91-71,78}$ & $\frac{43,34 \pm 10,07}{29,73-60,90}$ & $\frac{54,99 \pm 13,51}{40,82-67,73}$ & $\frac{25,29 \pm 8,38}{16,49-35,79}$ \\
\hline $\begin{array}{l}\text { Каверновая порстость*, \% } \\
\text { Vuggy porosity, \% }\end{array}$ & $\frac{2,41 \pm 3,33}{0,00-18,20}$ & $\frac{4,72 \pm 5,68}{0,21-20,55}$ & $\frac{19,84 \pm 14,09}{0,64-40,79}$ & $\frac{24,03 \pm 15,57}{0,00-46,31}$ & $\frac{21,18 \pm 22,99}{0,42-45,89}$ & $\frac{63,20 \pm 6,71}{54,08-68,47}$ \\
\hline $\begin{array}{l}\text { ИСФ, \% } \\
\text { FFI, \% }\end{array}$ & $\frac{28,27 \pm 13,84}{5,98-70,58}$ & $\frac{39,95 \pm 22,10}{10,85-74,91}$ & $\frac{68,92 \pm 15,27}{45,63-84,85}$ & $\frac{67,37 \pm 16,08}{38,70-88,94}$ & $\frac{76,16 \pm 9,54}{68,15-86,71}$ & $\frac{88,50 \pm 2,67}{84,50-89,97}$ \\
\hline $\begin{array}{l}\text { ИСФ/ИСВ } \\
\text { FFI/BVI }\end{array}$ & $\frac{0,47 \pm 0,44}{0,06-2,40}$ & $\frac{0,98 \pm 0,96}{0,12-2,99}$ & $\frac{2,94 \pm 1,75}{0,84-5,47}$ & $\frac{2,89 \pm 2,07}{0,63-8,05}$ & $\frac{3,82 \pm 2,37}{2,14-6,53}$ & $\frac{7,99 \pm 1,70}{5,45-8,97}$ \\
\hline $\mathrm{T}_{2}$ mode, $\mathrm{Mc}(\mathrm{ms})$ & $\frac{74,07 \pm 71,03}{13,51-451,30}$ & $\frac{109,02 \pm 61,55}{30,35-203,10}$ & $\frac{525,53 \pm 356,77}{130,60-1117,00}$ & $\frac{590,09 \pm 359,33}{55,03-1117,00}$ & $\frac{492,13 \pm 418,13}{174,30-965,80}$ & $\frac{1812,25 \pm 179,70}{1650,00-2056,00}$ \\
\hline $\mathrm{T}_{2} \operatorname{logmean}, \mathrm{Mc}(\mathrm{ms})$ & $\frac{54,65 \pm 33,57}{12,63-179,28}$ & $\frac{88,15 \pm 48,78}{28,54-169,53}$ & $\frac{255,43 \pm 123,72}{99,75-461,98}$ & $\frac{291,01 \pm 136,59}{34,86-520,41}$ & $\frac{257,23 \pm 201,26}{113,40-487,22}$ & $\frac{691,65 \pm 95,20}{574,76-795,68}$ \\
\hline
\end{tabular}

Примечание: в числителе указаны среднее арифметическое значение \pm среднее квадратическое отклонение, в знаменателе - размах значений; * - вклад в общую пористость.

Note: numarator is arithmetic mean value \pm standard deviation, denominator is value range; * - percent of total porosity. 


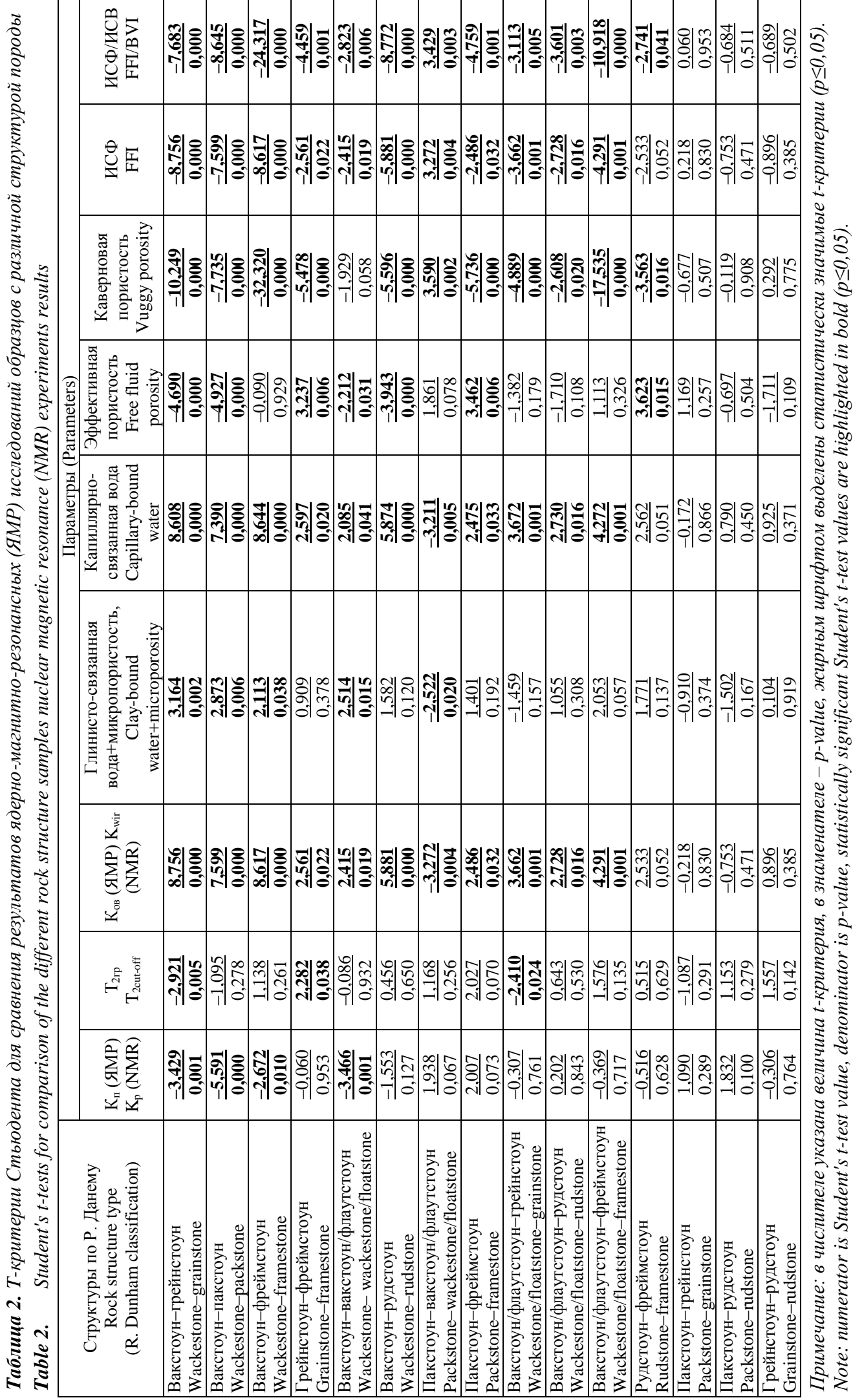

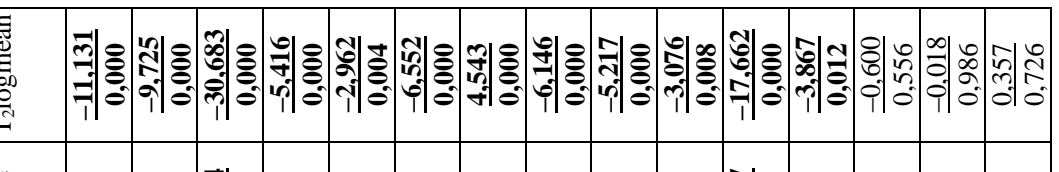

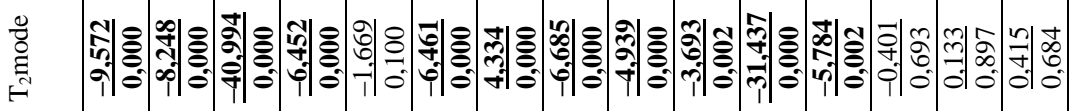

er

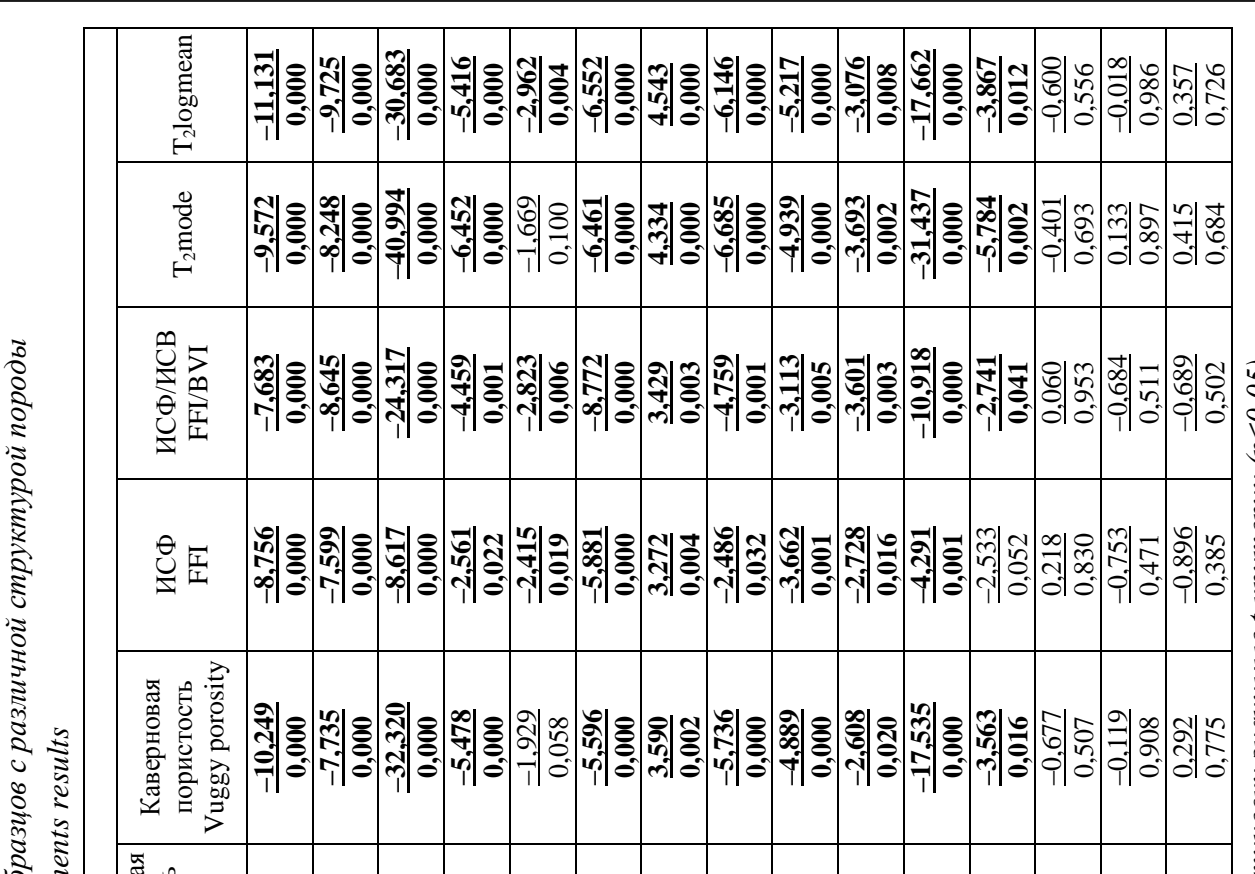
2
2
V
8
$\vdots$
8
$\vdots$
$\vdots$ 
Для сравнения распределений времен поперечной релаксации $\mathrm{T}_{2}$ образцов был проведен корреляционный анализ [23]: сопоставлены ЯМР-интенсивности конкретных времен поперечной релаксации $\mathrm{T}_{2}$, соответствующие разным образцам. Всего было определено 4095 коэффициентов корреляции. В табл. 3 приведено распределение коэффициентов корреляции разной величины для образцов с различной структурой породы по Р. Данему. По таблице видно, что для всех образцов (за исключением образцов со структурой рудстоун ввиду малого объема выборки) внутри одного класса (образцы с одинаковой структурой породы) наблюда- ется преобладание высоких $(0,7-0,9)$ и очень высоких $(0,9-1)$ коэффициентов корреляции, что свидетельствует о схожем характере распределений времен поперечной релаксации $\mathrm{T}_{2}$ для образцов $\mathrm{c}$ одинаковой структурой породы. При этом стоит отметить большое количество высоких и очень высоких коэффициентов корреляции при сравнении образцов со следующими структурами: вакстоун-вакстоун/флаутстоун, пакстоун-грейнстоун, пакстоун-рудстоун, вакстоун/флаутстоун-рудстоун, грейнстоун-рудстоун. Это говорит о схожем строении пустотного пространства анализируемых групп образцов.

Таблица 3. Распределение коэффищиентов корреляции разной величины для образиов с различной структурой пороdbl (6\%)

Table 3. Distribution of different values correlation coefficients for different rock structure samples (\%)

\begin{tabular}{|c|c|c|c|c|c|}
\hline $\begin{array}{c}\text { Структуры по Р. Данему } \\
\text { Диапазон изменения коэффициента корреляции } \\
\text { Rock structure type (R. Dunham classification) } \\
\text { Range of coefficient correlation variation }\end{array}$ & $\begin{array}{c}0-0,3 \\
\text { (очень слабая } \\
\text { very weak) }\end{array}$ & $\begin{array}{c}0,3-0,5 \\
\text { (слабая } \\
\text { weak) }\end{array}$ & $\begin{array}{c}0,5-0,7 \\
\text { (средняя } \\
\text { moderate) }\end{array}$ & $\begin{array}{l}0,7-0,9 \\
\text { (высокая } \\
\text { strong) }\end{array}$ & $\begin{array}{c}0,9-1 \\
\text { (очень высокая } \\
\text { very strong) }\end{array}$ \\
\hline $\begin{array}{l}\text { Вакстоун } \\
\text { Wackestone }\end{array}$ & 0,93 & 5,19 & 19,39 & 64,63 & 9,86 \\
\hline $\begin{array}{l}\text { Пакстоун } \\
\text { Packstone }\end{array}$ & 3,57 & 14,29 & 17,86 & 53,57 & 10,71 \\
\hline $\begin{array}{l}\text { Вакстоун/флаутстоун } \\
\text { Wackestone/floatstone }\end{array}$ & 1,10 & 7,69 & 19,78 & 60,44 & 10,99 \\
\hline $\begin{array}{l}\text { Грейнстоун } \\
\text { Grainstone }\end{array}$ & 10,26 & 12,82 & 19,23 & 50,00 & 7,69 \\
\hline $\begin{array}{l}\text { Рудстоун } \\
\text { Rudstone }\end{array}$ & 33,33 & 0,00 & 33,33 & 33,33 & 0,00 \\
\hline $\begin{array}{l}\text { Фреймстоун } \\
\text { Framestone }\end{array}$ & 0,00 & 0,00 & 0,00 & 0,00 & 100,00 \\
\hline $\begin{array}{l}\text { Вакстоун-пакстоун } \\
\text { Wackestone-packstone }\end{array}$ & 33,93 & 23,98 & 25,00 & 14,54 & 2,55 \\
\hline $\begin{array}{l}\text { Вакстоун-вакстоун/флаутстоун } \\
\text { Wackestone-wackestone/floatstone }\end{array}$ & 1,90 & 8,89 & 23,18 & 57,14 & 8,89 \\
\hline $\begin{array}{l}\text { Вакстоун-грейнстоун } \\
\text { Wackestone-grainstone }\end{array}$ & 40,82 & 25,28 & 14,29 & 16,32 & 3,29 \\
\hline $\begin{array}{l}\text { Вакстоун-рудстоун } \\
\text { Wackestone-rudstone }\end{array}$ & 35,37 & 14,29 & 27,21 & 20,41 & 2,72 \\
\hline $\begin{array}{l}\text { Вакстоун-фреймстоун } \\
\text { Wackestone-framestone }\end{array}$ & 95,92 & 4,08 & 0,00 & 0,00 & 0,00 \\
\hline $\begin{array}{l}\text { Пакстоун-вакстоун/флаутстоун } \\
\text { Packstone-wackestone/floatstone }\end{array}$ & 19,64 & 16,07 & 22,32 & 40,18 & 1,79 \\
\hline $\begin{array}{l}\text { Пакстоун-грейнстоун } \\
\text { Packstone-grainstone }\end{array}$ & 4,81 & 11,54 & 22,12 & 50,00 & 11,53 \\
\hline $\begin{array}{l}\text { Пакстоун-рудстоун } \\
\text { Packstone-rudstone }\end{array}$ & 8,33 & 12,50 & 20,83 & 41,67 & 16,67 \\
\hline $\begin{array}{l}\text { Пакстоун-фреймстоун } \\
\text { Packstone-framestone }\end{array}$ & 31,25 & 25,00 & 18,75 & 21,88 & 3,12 \\
\hline $\begin{array}{l}\text { Вакстоун/флаутстоун-грейнстоун } \\
\text { Wackestone/floatstone-grainstone }\end{array}$ & 22,53 & 23,08 & 25,28 & 26,37 & 2,74 \\
\hline $\begin{array}{l}\text { Вакстоун/флаутстоун-рудстоун } \\
\text { Wackestone/floatstone-rudstone }\end{array}$ & 23,81 & 14,29 & 9,52 & 47,62 & 4,76 \\
\hline $\begin{array}{l}\text { Вакстоун/флаутстоун-фреймстоун } \\
\text { Wackestone/floatstone-framestone }\end{array}$ & 89,28 & 5,36 & 5,36 & 0,00 & 0,00 \\
\hline $\begin{array}{l}\text { Грейнстоун-рудстоун } \\
\text { Grainstone-rudstone }\end{array}$ & 10,26 & 7,69 & 30,77 & 43,59 & 7,69 \\
\hline $\begin{array}{l}\text { Грейнстоун-фреймстоун } \\
\text { Grainstone-framestone }\end{array}$ & 26,93 & 11,54 & 38,46 & 21,15 & 1,92 \\
\hline $\begin{array}{l}\text { Рудстоун-фреймстоун } \\
\text { Rudstone-framestone }\end{array}$ & 41,68 & 25,00 & 16,67 & 16,67 & 0,00 \\
\hline
\end{tabular}

$\mathrm{C}$ целью наглядной визуализации на рис. 1 представлены осредненные распределения нормализованных ЯМР-интенсивностей по временам поперечной релаксации $\mathrm{T}_{2}$ для образцов с разной структурой породы. Под графиком представлены вклады различных типов пористостей в общую пористость (границы проведены по общепринятым отсечкам [22]). Данные кривые отражают наиболее вероятное время поперечной релаксации $\mathrm{T}_{2}$, а следовательно, и размер пор, который вносит наибольший вклад в объем пустотного про- 
странства. Приведенный график отображает структуру пустотного пространства, характерную для образцов с определенной структурой породы. По рисунку видно, что группы образцов со структурой породы вакстоун и вакстоун/флаутстоун, а также рудстоун, пакстоун и грейнстоун слабо отличаются по виду своих кривых.
Статистический анализ результатов ЯМРисследований образцов керна отображает целесообразность объединения выделенных групп в три класса: вакстоун и вакстоун/флаутстоун (1 класс); рудстоун, пакстоун и грейнстоун (2 класс); фреймстоун (3 класс).

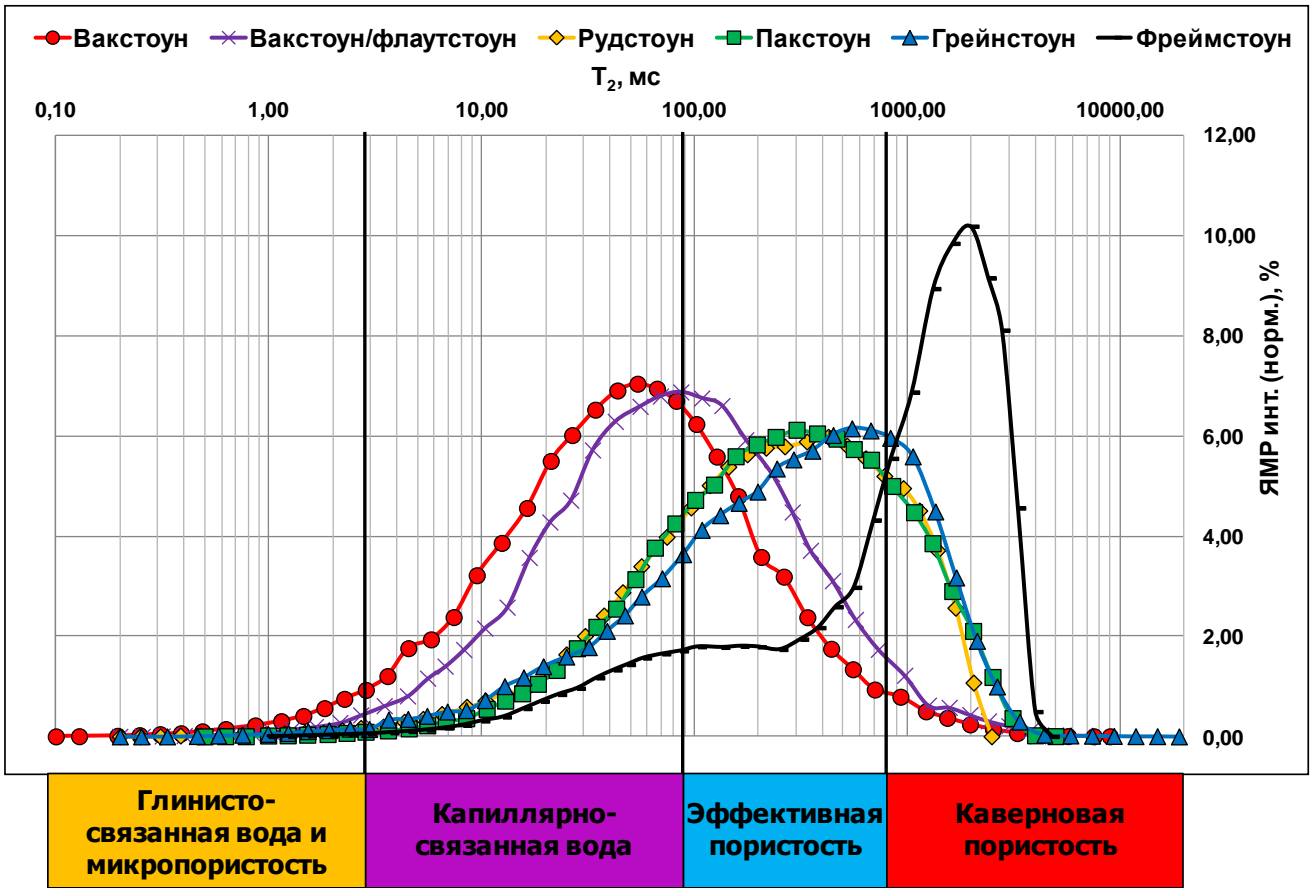

Рис. 1. Осредненные распределения нормализованных ЯМР-интенсивностей по временам поперечной релаксации $T_{2}$ различных групп образиов с одинаковой структурой породы

Fig. 1. Averaged distributions of normalized NMR intensities over transverse relaxation times $T_{2}$ of different rock structure samples groups

Согласно В.Г. Кузнецову, «первичные коллекторские свойства пород, тип пустотного пространства и величина пористости, а также тип вторичных преобразований и характер возникающей при этом вторичной пористости во многом определяются первичной структурой. Они различны для биогермных известняков - баундстоунов, зернистых пород - пакстоунов, грейстоунов, флаутстоунов и рудстоунов, причем тип зерен имеет сугубо подчиненное значение, и, наконец, микрозернистых - мадстоунов и вакстоунов» [19], что также подтверждается по результатам ЯМРисследований.

На рис. 2 представлены осредненные распределения нормализованных ЯМР-интенсивностей по временам поперечной релаксации $\mathrm{T}_{2}$ для выделенных классов образцов: петротипы достаточно хорошо дифференцируются по данным ЯМР-исследований. Под графиком представлены вклады различных типов пористостей в общую пористость (границы проведены по общепринятым отсечкам [22]). Также над графиком показаны фотографии шлифов, соответствующие различным классам. По фотографиям видно, что от 1 класса к 3 классу размер пор увеличивается, что подтверждается результатами ЯМР-исследований.

Основным критерием, определяющим тип коллектора, является способность породы пропускать через себя флюид при наличии перепада давления, то есть проницаемость. В зависимости от того, по каким пустотам преобладает фильтрация флюида, внутри каждого выделенного класса образцы были разделены на несколько групп. Результаты представлены на рис. 3. В результате аппроксимации данных получены следующие зависимости:

1) для образцов 1 класса:

- каверново-поровый тип коллектора:

$$
\mathrm{K}_{\text {пр }}=4 * 10^{-5} \mathrm{~K}_{\text {оп }}^{4,07}, \mathrm{R}^{2}=0,79 ;
$$

- трещинно-каверново-поровый тип коллектора:

$$
\mathrm{K}_{\text {пр }}=0,52 \mathrm{~K}_{\text {оп }}^{1,52}, \mathrm{R}^{2}=0,39 ;
$$

2) для образцов 2 класса:

- каверново-поровый тип коллектора:

$$
\mathrm{K}_{\text {пр }}=3 * 10^{-5} \mathrm{~K}_{\text {оп }}^{4,42}, \mathrm{R}^{2}=0,91 ;
$$

- трещинно-каверново-поровый тип коллектора:

$$
\mathrm{K}_{\text {пр }}=1,04 \mathrm{~K}_{\text {оп }}^{1,66}, \mathrm{R}^{2}=0,35 ;
$$

3) для образцов 3 класса:

- трещинно-каверново-поровый тип коллектора: уравнение связи не выведено.

По рис. 3 видно, что при одинаковой величине открытой пористости значения проницаемости среди образцов с одинаковым типом коллектора отличаются 
для выделенных классов - наблюдается увеличение от 1 к 3 классу. Это говорит о различии в размерах проводящих каналов. Стоит отметить, что анализ зависимостей $\mathrm{K}_{\text {пр }}=\mathrm{f}\left(\mathrm{K}_{\text {оп }}\right)$ не позволяет с высокой достоверностью выделять петрофизические типы пород.
Это связано с тем, что коэффициенты открытой пористости и проницаемости являются интегральными характеристиками и не дают детальной картины строения пустотного пространства пород.
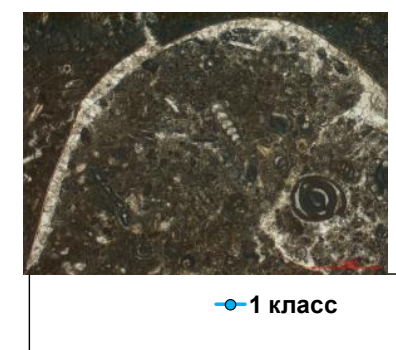

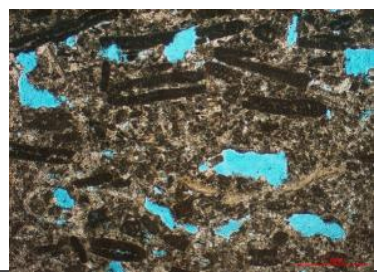

-2 класс

$\mathrm{T}_{2}, \mathrm{\text {мс }}$

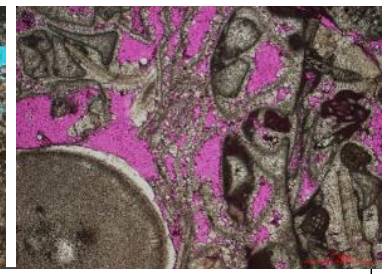

- класс

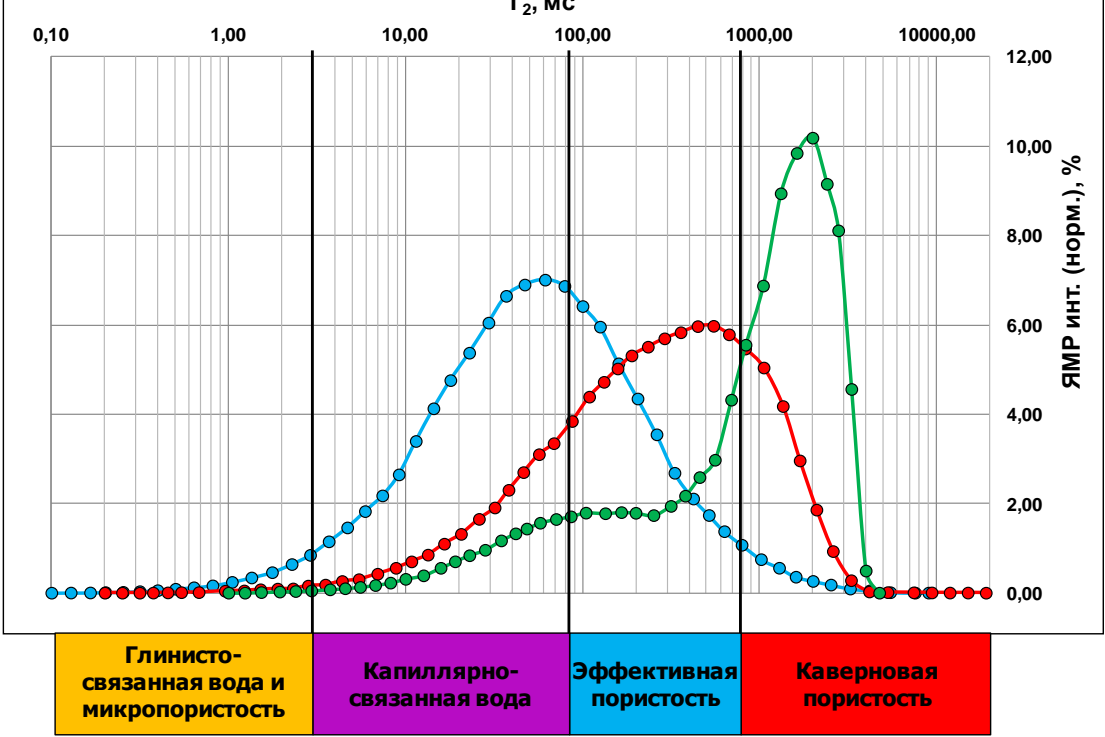

Рис. 2. Осредненные распределения нормализованных ЯМР-интенсивностей по временам поперечной релаксаиии $T_{2}$ выделенных петрофизических типов

Fig. 2. Averaged distributions of normalized NMR intensities over transverse relaxation times $T_{2}$ of identified petrophysical rock types

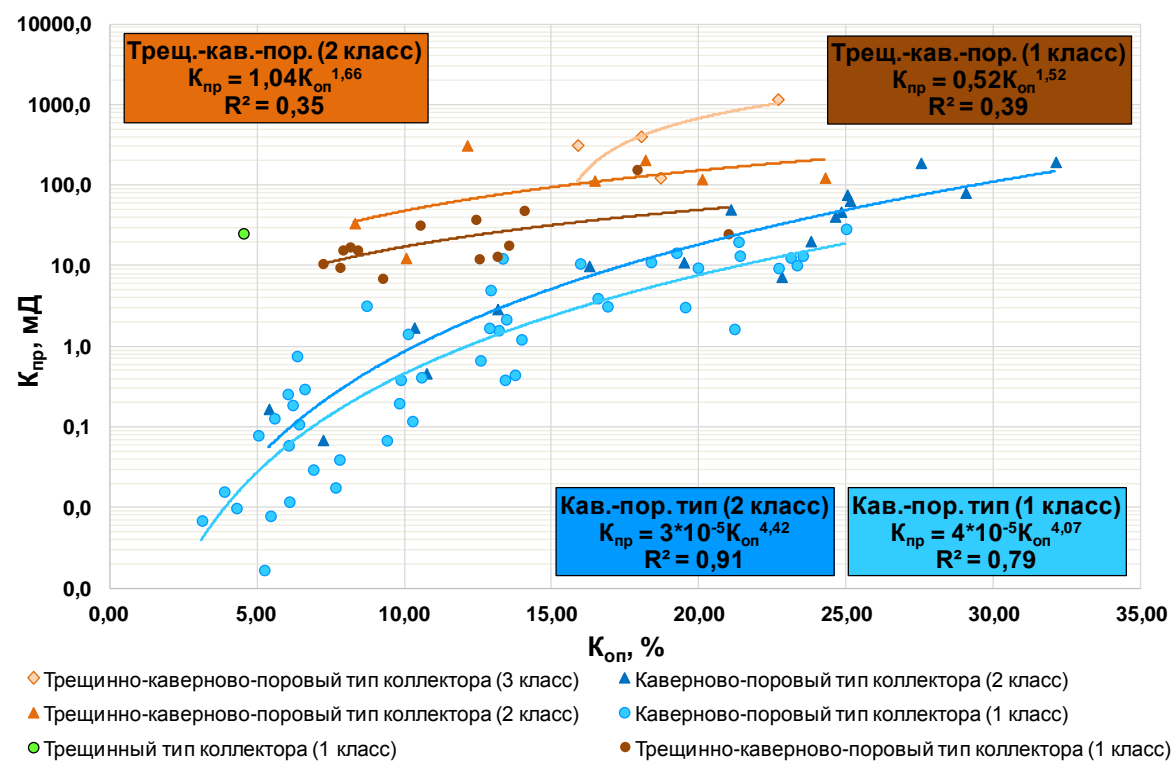

Рис. 3. Зависимость коэффищиента абсолютной газопронииаемости (с учетом поправки Клинкенберга) от коэффициента открытой пористости

Fig. 3. Relationship between coefficient of absolute permeability to gas (Klinkenberg-corrected) and coefficient of effective porosity 
На рис. 4 представлена зависимость параметра пористости от коэффициента открытой пористости раздельно по выделенным классам. В результате аппроксимации экспериментальных данных функцией Дахнова-Арчи [24] получены следующие зависимости для образцов:

1) 1 класса:

$$
\mathrm{P}_{\Pi}=1,15 \mathrm{~K}_{\text {оп }}^{-1,79}, \mathrm{R}^{2}=0,97 ;
$$

2) 2 класса:

$$
\mathrm{P}_{\Pi}=0,95 \mathrm{~K}_{\mathrm{0 \Pi}}^{-2,02}, \mathrm{R}^{2}=0,97 ;
$$

3) 3 класса:

$$
\mathrm{P}_{\Pi}=0,99 \mathrm{~K}_{\text {оп }}^{-2,13}, \mathrm{R}^{2}=0,99 .
$$

По приведенным зависимостям видно, что показатель цементации (m) возрастает от 1 к 3 классу, что говорит о межзерновой пористости для пород 1 класca $(\mathrm{m}=1,79)$, и каверново-межзерновой для пород 2 и 3 классов (m=2,02 и 2,13 соответственно), причем для 3 класса доля каверновой составляющей выше, что также подтверждается результатами ЯМРисследований.

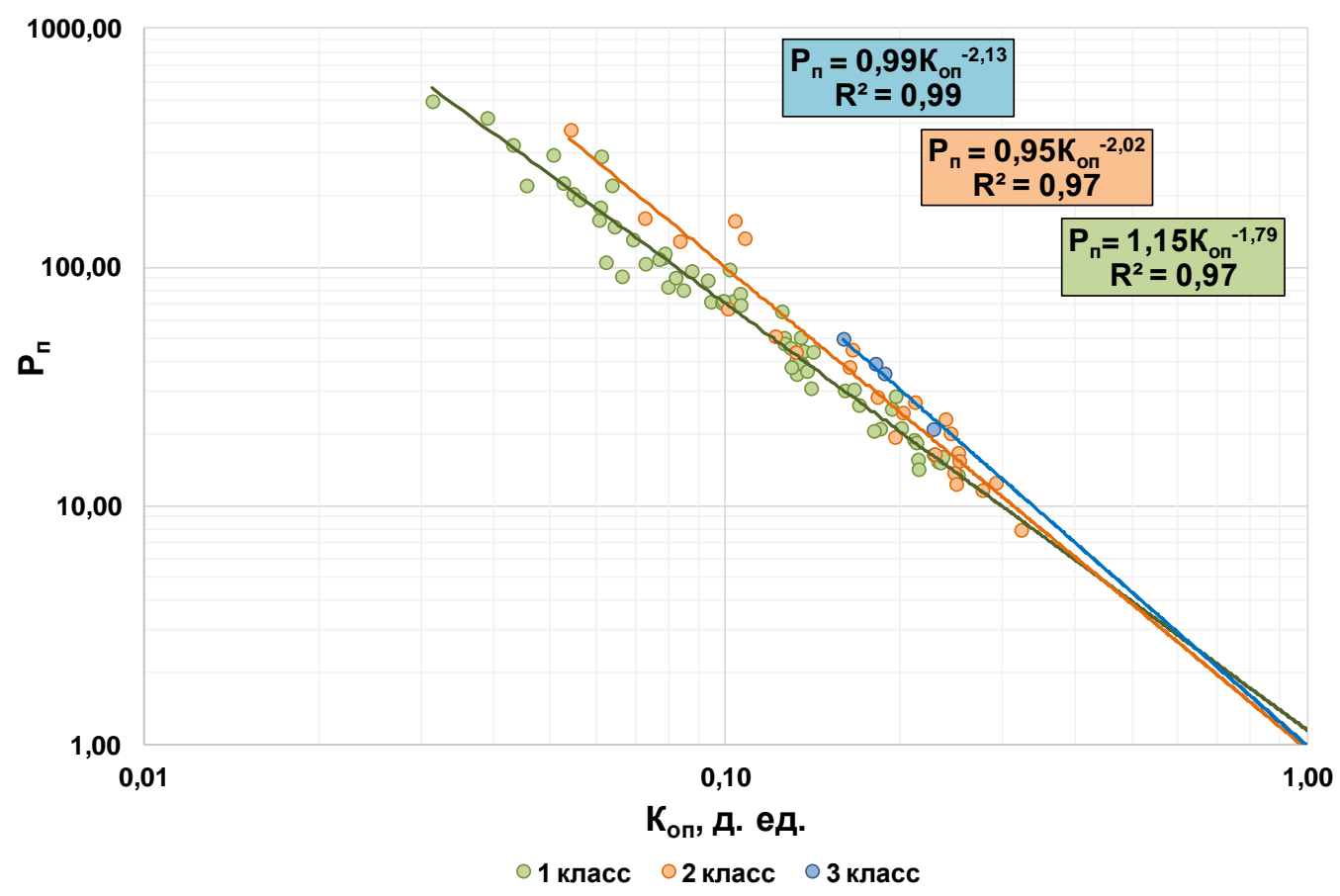

Pис. 4. Зависимость параметра пористости от коэффициента открытой пористости

Fig. 4. Relationship between formation factor and coefficient of effective porosity

Применение методов главных компонент и линейного дискриминантного анализа при выделении петрофизических типов пород

Для оценки правильности выделения петрофизических типов пород были применены методы главных компонент и дискриминантного анализа.

Основными задачами метода главных компонент является сокращение числа переменных и изучение скрытой структуры взаимосвязей между переменными, то есть их классификация (один из методов классификации «без учителя») [23].

В результате применения данного метода осуществляется переход от исходных переменных к новым, которые носят название главных компонент. В данной работе в качестве исходных переменных выступают значения ЯМР-интенсивностей, соответствующие определенным интервалам времен поперечной релаксации $(0-0,1 \mathrm{Mc}, 0,1-0,2 \mathrm{Mc}, 0,2-0,3$ мс ... 1-2 мс, 2-3 мс, 3-4 мс ... 10-20 мс, 20-30 мс, 30-40 мс и т. д.). В результате применения метода главных компонент из 47 исходных переменных были получены 45 новых, причем наиболее информативными (с величиной собственного значения более 1) являются 11 главных компонент, которые объясняют 82,63% от общей дисперсии. На рис. 5 представлено расположение выделенных классов образцов в осях Фактор 1 и Фактор 2, которые являются новыми переменными, вносящими наибольший вклад в объяснение общей дисперсии (26,02 и 13,19 \% соответственно). По приведенному рисунку видно, что точки, соответствующие образцам различных классов, достаточно хорошо дифференцируются в пределах данного поля.

Другим широко используемым при решении геологических задач методом является дискриминантный анализ $[25,26]$. Метод заключается в построении на основе исходных переменных дискриминантных функций, позволяющих максимально возможно разделить априорно выделенные группы объектов. В данной работе для получения линейных дискриминантных функций использовались показатели, полученные в результате интерпретации данных ЯМРисследований. В результате расчетов в модель были включены семь переменных и получены следующие линейные дискриминантные функции (коэффициенты перед переменными - стандартизованные): 


$$
\begin{gathered}
\mathrm{Z}_{1}=1,80937 \mathrm{~T}_{2} \text { logmean }+0,18717 \mathrm{~K}_{\text {ов }}-0,40135 \mathrm{~T}_{2 \text { гр }} \\
+0,63618\left(\frac{\mathrm{FFI}}{\mathrm{BVI}}\right)-1,11029 \kappa_{\text {эфп }}+0,30135 \mathrm{~K}_{\text {п }} \\
-0,71870 \text { (Кав. пор.), }
\end{gathered}
$$

при $\mathrm{R}=0,922, \chi^{2}=221,9151, \mathrm{p}=0,000000$;

$$
\begin{gathered}
\mathrm{Z}_{2}=-0,55670 \mathrm{~T}_{2} \operatorname{logmean}-0,88176 \mathrm{~K}_{\text {ов }}+0,63057 \mathrm{~T}_{2 г \mathrm{p}} \\
-0,73491\left(\frac{\mathrm{FFI}}{\mathrm{BVI}}\right)+1,54409 \kappa_{\text {эфп }}-0,90435 \mathrm{~K}_{\mathrm{n}} \\
+0,27914 \text { (Кав. пор. }),
\end{gathered}
$$

при $\mathrm{R}=0,719, \chi^{2}=61,3824, \mathrm{p}=0,000000$.

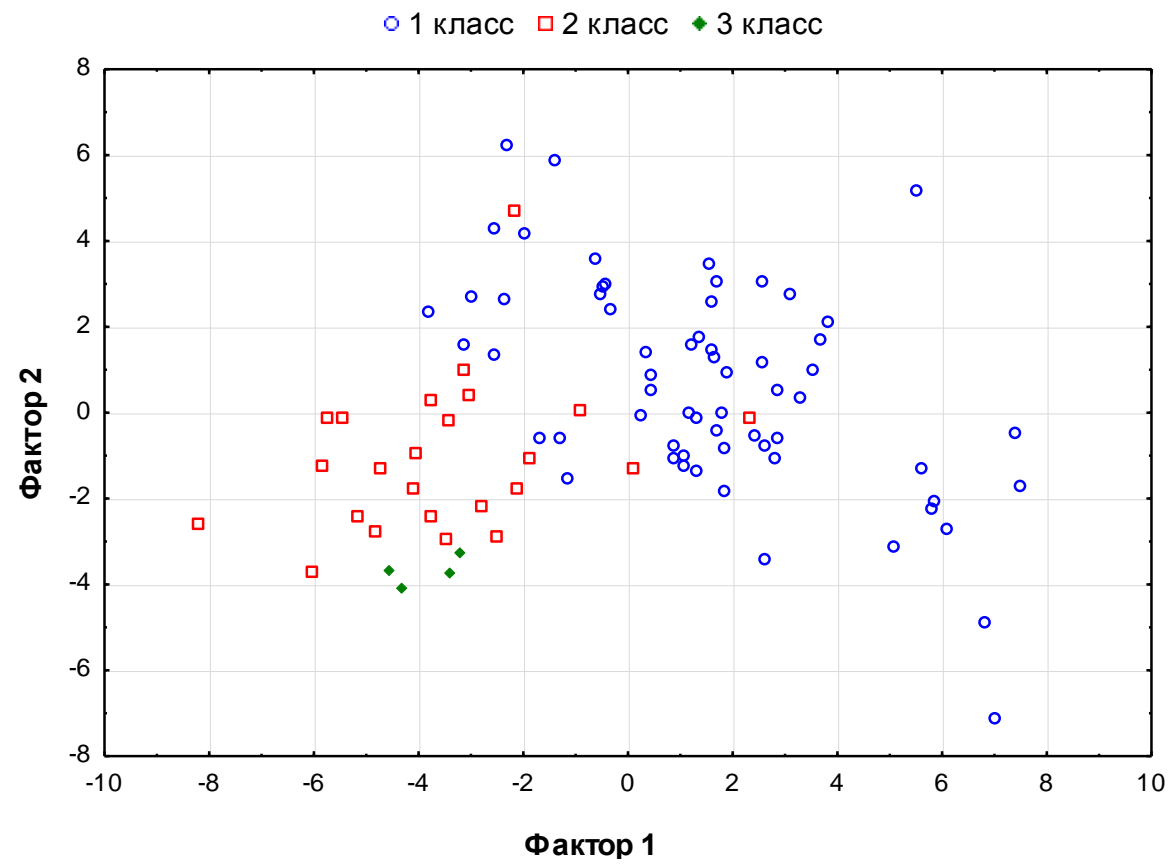

Pис. 5. Соотношение значений факторов 1 и 2 для выделенных классов

Fig. 5. Correlation of factor 1 and 2 values for identified classes

○ 1 класс в 2 класс • 3 класс

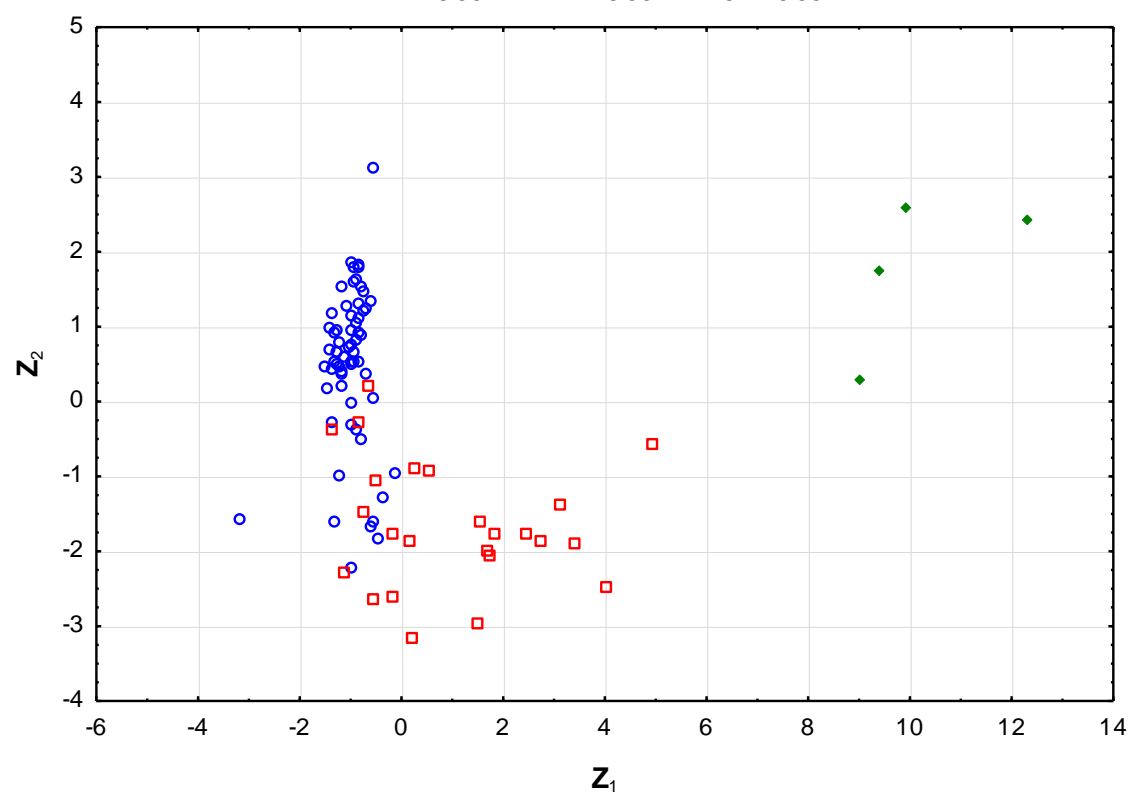

Pис. 6. Распределение значений $Z_{1}$ и $Z_{2}$ для выделенных классов

Fig. 6. Distribution of $Z_{1}$ and $Z_{2}$ values for identified classes

По данным функциям были вычислены значения $\mathrm{Z}_{1}$ и $\mathrm{Z}_{2}$, которые для различных выделенных классов приведены на рис. 6. По приведенному графику видно, что значения $Z_{1}$ и $Z_{2}$ достаточно хорошо разделя- ются в пределах выделенных петрофизических типов (Лямбда Уилкса составляет 0,08096). Среднее значение $Z_{1}$ для 1 класса равно $-1,005$, для 2 класса $+1,063$, для 3 класса $+9,443$. Среднее значение $Z_{2}$ для 1 класса 
составляет $-0,488$, для 2 класса $+1,598$, для 3 класса 1,898. Достоверность распознавания образцов 1 класса составляет 93,7 \%, 2 класса - 79,2 \%, 3 класса $100,0 \%$, что значительно выше, чем до объединения групп образцов с различной структурой породы в классы. Основными параметрами, вносящими больший вклад в разделение, являются среднее логарифмическое значение времен поперечной релаксации ( $\left.\mathrm{T}_{2} \operatorname{logmean}\right)$ (для первой дискриминантной функции) и коэффициент эффективной пористости $\left(\mathrm{K}_{\text {эфп }}\right)$ (для второй дискриминантной функции).

Неопределенности, возникающие при классификации, связаны со степенью проявления вторичных (постседиментационных) преобразований пустотного пространства. Накопление большего объема фактического материала в дальнейшем позволит повысить точность выделения петрофизических типов.

Полученные дискриминантные функции позволяют на основании результатов ЯМР-исследований образцов керна, отобранного из скважин изучаемого месторождения, относить их с определенной долей вероятности к выделенному классу.

Результаты проведенного анализа показывают, что по результатам ЯМР-исследований с учетом литологических особенностей пород возможно выделение петрофизических типов, характеризующихся различной структурой пустотного пространства и, следовательно, ФЕС.

\section{Заключение}

В ходе выполнения данной работы были получены следующие выводы и результаты:

\section{СПИСОК ЛИТЕРАТУРЫ}

1. Coates G.R., Xiao L., Prammer M.G. NMR logging. Principles and applications. - Houston: Halliburton Energy Services, 1999. $253 \mathrm{p}$.

2. Джафаров И.С., Сынгаевский П.Е., Хафизов С.Ф. Применение метода ЯМР для характеристики состава и распределения пластовых флюидов. - М.: Химия, 2002. - 439 с.

3. Looyestijn W., Zhang X., Hebing A. How can NMR asses the wettability of a chalk reservoir // International Symposium of the Society of Core Analysts. - Vienna, Austria, 2017. - P. 1-12.

4. Dick M.J., Veselinovic D., Green D. Spatially resolved wettability measurements using NMR wettability index // International Symposium of the Society of Core Analysts. - Trondheim, Norway, 2018 - P. 1-12.

5. Quick and simple porosity measurement at the well site / M.J. Dick, D. Green, T. Kenney, D. Veselinovic, J. Tallarita, M.A. Smith // International Symposium of the Society of Core Analysts. - Vienna, Austria, 2017. - P. 1-10.

6. Brandimarte F., Eriksson M., Moss A. How to obtain primary drainage capillary pressure curves using NMR T2 distributions in a heterogeneous carbonate reservoir // International Symposium of the Society of Core Analysts. - Vienna, Austria, 2017. - P. 1-9.

7. Valori A., Nicot B. A review of 60 years of NMR wettability // International Symposium of the Society of Core Analysts. Trondheim, Norway, 2018. - P. 1-13.

8. Measuring relative permeability with NMR / M.J. Dick, D. Veselinovic, T. Kenney, D. Green // International Symposium of the Society of Core Analysts. - Trondheim, Norway, 2018 P. $1-10$.

9. Злобин А.А. Теория и практика применения ядерного магнитного резонанса в физике нефтяного пласта. - Пермь: Изд-во $\Pi$ П 2015. $-271 \mathrm{c}$

10. Оценка лиофильности пород баженовской свиты методами адсорбции и ядерной магнитной релаксометрии / С.А. Бори-
1. Показано, что вид кривых времен поперечной релаксации $\mathrm{T}_{2}$ (следовательно, и структура пустотного пространства) определяется первичной структурой породы, а также характером и степенью постседиментационных преобразований.

2. Анализ результатов ЯМР-исследований керна подтвердил, что коллекторские свойства и тип пустотного пространства во многом определяются первичной структурой. Они различны для микрозернистых пород (1 класс), зернистых пород (2 класс), причем тип зерен имеет сугубо подчиненное значение, и биогермных известняков (3 класс).

3. По данным ЯМР-исследований с учетом результатов микроописания шлифов в изучаемом разрезе выделены три петрофизических типа пород.

4. По результатам интерпретации данных ЯМРисследований построены линейные дискриминантные функции, которые позволяют на основании результатов ЯМР-исследований образцов керна, отобранного из скважин изучаемого месторождения, относить их с определенной долей вероятности к выделенному классу.

5. Дальнейшие работы по данной теме должны быть связаны с накоплением большего объема фактического материала с целью повышения точности выделения петрофизических типов, а также адаптации данных лабораторных ЯМР-исследований к скважинному ядерному магнитному каротажу.

Полученная информация позволяет дифференцированно подходить к петрофизическому моделированию изучаемой залежи, являющемуся основой построения геологической модели.

сенко, Н.Н. Богданович, Е.В. Козлова, М.Ю. Спасенных, Д.Е. Заграновская // Нефтяное хозяйство. - 2017. - № 3. C. $12-16$.

11. Эффективность применения метода ядерно-магнитного резонанса при лабораторных петрофизических исследованиях керна и шлама / В.А. Вавилин, А.А. Кунакасов, Т.Р. Галиев, Е.В. Сорокина // Нефтяное хозяйство. - 2011. - № 8. - С. 21-23.

12. Кулявцев А.В., Федорцов И.В. Результаты опытнопромышленных работ по использованию ЯМР-релаксометра $\mathrm{GeoSpec}$ для измерения общей и эффективной пористости горных пород // Нефтяное хозяйство. - 2017. - № 9. - С. 34-36.

13. Закревский К.Е., Кундин А.С. Особенности геологического 3D моделирования карбонатных и трещинных резервуаров. М.: ООО «Белый Ветер», 2016. - 404 с.

14. Лусиа Ф.Дж. Построение геолого-гидродинамической модели карбонатного коллектора: интегрированный подход. - М.; Ижевск: НИЦ «Регулярная и хаотическая динамика», Ижевский институт компьютерных исследований, 2010. - 384 с.

15. Kolodzie S. Jr. Analysis of pore throat size and use of the Waxman-Smits equation to determine OOIP in Spindle Field, Colorado // The 55th Annual Fall Technical Conference and Exhibition of the Society of Petroleum Engineers of AIME. Dallas, Texas, the USA, 1980. - P. 1-10.

16. Enhanced reservoir description: using core and log data to identify Hydraulic (Flow) Units and predict permeability in uncored intervals/wells / J.O. Amaefule, M. Altunbay, D. Tiab, D.G. Kersey, D.K. Keelan // The 68th Annual Technical Conference and Exhibition of the Society of Petroleum Engineers. - Houston, Texas, the USA, 1993. - P. 205-220.

17. Skalinski M., Kenter J. Carbonate petrophysical rock typing integrating geological attributes and petrophysical properties while linking with dynamic behavior // The SPWLA 54th Annual Logging Symposium. - New Orleans, Lousiana, the USA, 2013. P. 1-11. 
18. Бакиров А.А., Варенцов М.И., Бакиров Э.А. Нефтегазоносные провинции и области зарубежных стран. - М.: Изд-во «Недра», 1971. $-544 \mathrm{c}$.

19. Кузнецов В.Г. Литология. Осадочные горные породы и их изучение. - М.: ООО «Недра-Бизнесцентр», 2007. -511 с.

20. Кобранова В.Н. Петрофизика. - М.: Недра, 1986. -392 с.

21. Топорков В.Г., Денисенко А.С. Практическое применение данных ЯМР для оценки свойств и структуры пород продуктивных нефтегазоносных залежей // Каротажник. - 2008. № 12. - C. 162-188.

22. Методические рекомендации по подсчету геологических запасов нефти и газа объемным методом / под ред. В.И. Петерсилье, В.И. Пороскуна, Г.Г. Яценко. - М.; Тверь: ВНИГНИ, НПЦ «Тверьгеофизика», 2003. - 258 с.

23. Девис Дж.С. Статистический анализ данных в геологии. - М.: Недра, 1990. - 319 с

24. Добрынин В.М., Вендельштейн Б.Ю., Кожевников Д.А. Петрофизика (Физика горных пород). - М.: Изд-во «Нефть и газ» РГУ нефти и газа им. И.М. Губкина, 2004. - 368 с.
25. Галкин В.И., Пономарева И.Н., Репина В.А. Исследование процесса нефтеизвлечения в коллекторах различного типа пустотности с использованием многомерного статистического анализа // Вестник Пермского национального исследовательского политехнического университета. Геология. Нефтегазовое и горное дело. - 2016. - Т. 15. - № 19. - С. 145-154. DOI: 10.15593/2224-9923/2016.19.5.

26. Способ оценки коэффициента вытеснения нефти на основе стандартных исследований керна / Е.А. Гладких, Г.П. Хижняк, В.И. Галкин, Н.А. Попов // Вестник Пермского национального исследовательского политехнического университета. Геология. Нефтегазовое и горное дело. - 2017. - Т. 16. - № 3. C. 225-237. DOI: $10.15593 / 2224-9923 / 2017.3 .3$.

Поступила 04.09.2020 г.

\section{Информация об авторах}

Путилов И.С., доктор технических наук, заместитель директора Филиала по научной работе в области геологии, Филиал ООО «ЛУКОЙЛ-Инжиниринг» «ПермНИПИнефть» в г. Перми.

$\boldsymbol{P a з н и ц ы н ~ A . B . , ~ и н ж е н е р ~ 2 - и ̆ ~ к а т е г о р и и ~ О т д е л а ~ ф и з и к и ~ п л а с т а ~ У п р а в л е н и я ~ к о м п л е к с н ы х ~ и с с л е д о в а н и и ̆ ~ к е р н а ~}$ Центра исследования керна и пластовых флюидов, Филиал ООО «ЛУКОЙЛ-Инжиниринг» «ПермНИПИнефть» в г. Перми. 
UDC 550.8.053

\title{
IDENTIFICATION OF CARBONATE ROCKS PETROPHYSICAL TYPES WITH NUCLEAR MAGNETIC RESONANCE EXPERIMENTS DATA TAKING INTO ACCOUNT THEIR LITHOLOGICAL CHARACTERISTICS
}

\author{
Ivan S. Putilov', \\ Ivan.Putilov@pnn.lukoil.com
}

\author{
Alexandr V. Raznitsyn ${ }^{1}$, \\ alexandrraznitsyn@gmail.com \\ 1 Branch of 000 «LUKOIL-Engineering» «PermNIPIneft» in Perm, \\ 3a, Permskaya street, Perm, 614015, Russia.
}

\begin{abstract}
The relevance. Significant part of world hydrocarbons reserves is confined to carbonate reservoirs, which are characterized by complex structure of voids. Reserves estimation and development design of such reservoirs require detailed study of porous media structure, that directly influences the reservoir properties. Identification of petrophysical rock classes is an integral part of hydrocarbons reservoir petrophysical model building. Nuclear magnetic resonance (NMR) method is one of the methods of rock porous structure research and has a number of advantages over other methods. However, there is no information in the published literature about application of this method for petrophysical typing. The results of petrophysical classes identification based on integration of NMR experiments and thin sections description data enhance the quality of reservoir geological and hydrodynamic simulation and hence improve accuracy of hydrocarbons reserves estimation and efficiency of field development.
\end{abstract}

The main aim of the research is carbonate rock petrophysical typing based on integration of NMR experiments and thin sections description data, and estimation of classes identification accuracy with the methods of mathematical statistics.

Object: carbonate rocks of Mishrif formation, which is productive in the field of Mesopotamian oil-and-gas province.

Methods: analysis of core sample NMR experiments results, thin sections description and routine core analysis, methods of mathematical statistics.

Results. Three petrophysical rock types are identified in the log of the well, which intersects productive deposits. The types are: $1^{\text {st }}$ class (wackestone and wackestone/floatstone rock structure), $2^{\text {nd }}$ class (packstone, grainstone and rudstone rock structure) and $3^{\text {rd }}$ class (framestone rock structure). These petrophysical classes are proved with statistical analysis results.

\section{Key words:}

Petrophysical type, nuclear magnetic resonance method, $R$. Dunham classification, transverse relaxation time, carbonate rocks, statistical analysis.

\section{REFERENCES}

1. Coates G.R., Lizhi Xiao, Prammer M.G. NMR Logging. Principles and Applications. Houston, Halliburton Energy Services Publ., 1999. $253 \mathrm{p}$.

2. Dzhafarov I.S., Syngaevskiy P.E., Khafizov S.F. Primenenie metoda YAMR dlya kharakteristiki sostava $i$ raspredeleniya plastovykh flyuidov [Application of the NMR method for characterization of reservoir fluids composition and distribution]. Moscow, Khimiya Publ., 2002. 439 p.

3. Looyestijn W., Zhang X., Hebing A. How can NMR asses the wettability of a chalk reservoir. International Symposium of the Society of Core Analysts. Vienna, Austria, SCA Publ., 2017. pp. $1-12$.

4. Dick M.J., Veselinovic D., Green D. Spatially resolved wettability measurements using NMR wettability index. International Symposium of the Society of Core Analysts. Trondheim, Norway, SCA Publ., 2018. pp. 1-12.

5. Dick M.J., Green D., Kenney T., Veselinovic D., Tallarita J., Smith M.A. Quick and simple porosity measurement at the well site. International Symposium of the Society of Core Analysts. Vienna, Austria, SCA Publ., 2017. pp. 1-10.

6. Brandimarte F., Eriksson M., Moss A. How to obtain primary drainage capillary pressure curves using NMR T2 distributions in a heterogeneous carbonate reservoir. International Symposium of the Society of Core Analysts. Vienna, Austria, SCA Publ., 2017. pp. $1-9$.

7. Valori A., Nicot B. A review of 60 years of NMR wettability. International Symposium of the Society of Core Analysts. Trondheim, Norway, SCA Publ., 2018. pp. 1-13.

8. Dick M.J., Veselinovic D., Kenney T., Green D.. Measuring relative permeability with NMR. International Symposium of the Society of Core Analysts. Trondheim, Norway, SCA Publ., 2018. pp. $1-10$.
9. Zlobin A.A. Teoriya $i$ praktika primeneniya yadernogo magnitnogo rezonansa $v$ fizike neftyanogo plasta [Theory and practice of nuclear magnetic resonance application in oil reservoir physics]. Perm, PM Publ., 2015. 271 p.

10. Borisenko S.A., Bogdanovich N.N., Kozlova E.V., Spasennykh M.Yu., Zagranovskaya D.E. Estimating lyophilic properties of the Bazhenov formation rocks by adsorption and NMR methods. Oil industry, 2017, no. 3, pp. 12-16. In Rus.

11. Vavilin V.A., Kunakasov A.A., Galiev T.R., Sorokina E.V. Effectiveness of nuclear magnetic resonance method use for core samples and drilling sludge laboratory petrophysical study. Oil industry, 2011, no. 8, pp. 21-23. In Rus.

12. Kulyavtsev A.V., Fedortsov I.V. Results of pilot-industrial works on the use of the GeoSpec NMR-relaxometer to measure the total and effective porosity of rocks. Oil industry, 2017, no. 9, pp. 34-36. In Rus.

13. Zakrevskiy K.E., Kundin A.S. Osobennosti geologicheskogo $3 D$ modelirovaniya karbonatnykh $i$ treshchinnykh rezervuarov [Special characteristics of 3D geological modeling of carbonate reservoirs]. Moscow, OOO «Bely Veter» Publ., 2016. 404 p.

14. Lusia F.Dzh. Postroenie geologo-gidrodinamicheskoy modeli karbonatnogo kollektora: integrirovanny podkhod [Carbonate reservoir characterization: an integrated approach]. Moscow, Izhevsk, NIC «Regulyarnaya i khaoticheskaya dinamika», Izhevsk Institute of Computer Research Publ., 2010. 384 p.

15. Kolodzie S.Jr. Analysis of pore throat size and use of the Waxman-Smits equation to determine OOIP in Spindle Field, Colorado. The $55^{\text {th }}$ Annual Fall Technical Conference and Exhibition of the Society of Petroleum Engineers of AIME. Dallas, Texas, the USA, SPE Publ., 1980. pp. 1-10.

16. Amaefule J.O., Altunbay M., Tiab D., Kersey D.G., Keelan D.K. Enhanced reservoir description: using core and log data to identify Hydraulic (Flow) Units and predict permeability in uncored 
intervals/wells. The $68^{\text {th }}$ Annual Technical Conference and Exhibition of the Society of Petroleum Engineers. Houston, Texas, the USA, SPE Publ., 1993. pp. 205-220.

17. Skalinski M., Kenter J. Carbonate petrophysical rock typing integrating geological attributes and petrophysical properties while linking with dynamic behavior. The SPWLA 54th Annual Logging Symposium. New Orleans, Lousiana, the USA, SPWLA Publ., 2013. pp. 1-11.

18. Bakirov A.A., Varencov M.I., Bakirov E.A. Neftegazonosnye provintsii $i$ oblasti zarubezhnykh stran [Oil-and-gas bearing provinces and regions of foreign countries]. Moscow, Nedra Publ., 1971. $544 \mathrm{p}$.

19. Kuznetsov V.G. Litologiya. Osadochnye gornye porody $i \mathrm{ikh}$ izuchenie [Lithology. Sedimentary rocks and study of them] Moscow, Nedra-Businesscenter Publ., 2007. 511 p.

20. Kobranova V.N. Petrofizika [Petrophysics]. Moscow, Nedra Publ., 1986. $392 \mathrm{p}$.

21. Toporkov V.G., Denisenko A.S. Prakticheskoe primenenie dannykh YAMR dlya otsenki svoystv i struktury porod produktivnykh neftegazonosnykh zalezhey [Practical application of the NMR data for estimation of productive oil-and-gas bearing accumulations rocks properties and structure]. Karotazhnik, 2008, no. 12 , pp. $162-188$.

Information about the authors

Ivan S. Putilov, Dr. Sc., deputy director, the Branch of OOO «LUKOIL-Engineering» «PermNIPIneft» in Perm. Alexandr V. Raznitsyn, $2^{\text {nd }}$ category engineer, the Branch of OOO «LUKOIL-Engineering» «PermNIPIneft» in Perm.
22. Metodicheskie rekomendatsii po podschetu geologicheskikh zapasov nefti $i$ gaza obyemnym metodom [Methodological recommendations for oil and gas reserves estimation with volumetric method]. Eds. V.I. Petersilye, V.I. Poroskun, G.G. Yatsenko. Moscow, Tver, Tvergeophizika Publ., 2003. 258 p.

23. Devis Dzh.S. Statisticheskiy analiz dannykh v geologii [Statistics and data analysis in geology]. Moscow, Nedra Publ., 1990. 319 p.

24. Dobrynin V.M., Vendelshteyn B.Yu., Kozhevnikov D.A. Petrofizika (Fizika gornykh porod) [Petrophysics: physics of rocks]. Moscow, «Neft i gas» Publ., 2004. 368 p.

25. Galkin V.I., Ponomareva I.N., Repina V.A. Study of oil recovery from reservoirs of different void types with use of multidimensional statistical analysis. Bulletin of PNRPU. Geology. Oil and gas engineering and mining, 2016, vol. 15, no. 19, pp. 145-154. In Rus. DOI: 10.15593/2224-9923/2016.19.5.

26. Gladkikh E.A., Khizhnyak G.P., Galkin V.I., Popov N.A. Method for evaluation of oil displacement coefficient based on conventional core analysis. Bulletin of PNRPU. Geology. Oil and gas engineering and mining, 2017. vol. 16. no. 3. pp. 225-237. In Rus. DOI: 10.15593/2224-9923/2017.3.3.

Received: 4 September 2020. 